\title{
Multivariate Path Analysis of Serum 25-Hydroxyvitamin D Concentration, Inflammation, and Risk of Type 2 Diabetes Mellitus
}

\author{
Shaum M. Kabadi, Longjian Liu, Amy H. Auchincloss, and Issa F. Zakeri \\ Department of Epidemiology and Biostatistics, Drexel University School of Public Health, 1505 Race Street, \\ Bellet Building 6th Floor, Philadelphia, PA 19102, USA
}

Correspondence should be addressed to Longjian Liu; 1185@drexel.edu

Received 13 June 2013; Revised 9 August 2013; Accepted 11 August 2013

Academic Editor: Luisella Bocchio-Chiavetto

Copyright (C) 2013 Shaum M. Kabadi et al. This is an open access article distributed under the Creative Commons Attribution License, which permits unrestricted use, distribution, and reproduction in any medium, provided the original work is properly cited.

Background and Aims. Despite growing interest in the protective role that vitamin D may have in health outcomes, little research has examined the mechanisms underlying this role. This study aimed to test two hypotheses: (1) serum 25-hydroxyvitamin D $[25(\mathrm{OH}) \mathrm{D}]$ is inversely associated with type 2 diabetes mellitus (T2DM) and elevated hemoglobin Alc; (2) these associations are mediated by serum C-reactive protein (CRP). Methods. Participants aged 20 and older in 2001-2006 National Health and Nutrition Examination Surveys $(n=8,655)$ with measures of serum $25(\mathrm{OH}) \mathrm{D}$, CRP, hemoglobin Alc, and other important covariates were included in the present study. Logistic regression and path analysis methods were applied to test the study hypotheses. Results. Decreased serum 25(OH)D concentration was significantly associated with increased odds of T2DM. In males, an estimated $14.9 \%$ of the association between 25(OH)D and hemoglobin Alc was mediated by serum CRP. However, this mediation effect was not observed in females. Conclusion. Using a nationally representative sample, the present study extends previous research and provides new evidence that the effect of decreased serum vitamin D concentration on T2DM may proceed through increased systemic inflammation in males. Longitudinal studies and randomized control trials are needed to confirm the present findings.

\section{Introduction}

Systematic review studies indicate that high serum $25(\mathrm{OH}) \mathrm{D}$ concentration (a biomarker of vitamin D status in blood) may be associated with lower risk of T2DM [1-4]. Although the mechanism by which decreased serum $25(\mathrm{OH}) \mathrm{D}$ concentration increases risk of T2DM remains obscure, it has been suggested that vitamin $\mathrm{D}$ deficiency may cause diabetes through various pathways including impaired pancreatic $\beta$ cell function, insulin resistance, and systemic inflammation $[5,6]$. Furthermore, the presence of vitamin D receptors on inflammatory cells suggests that there is a potential role for vitamin D in inflammation [7]. Because the activation of inflammatory pathways may downregulate insulin signaling which can cause insulin resistance, vitamin D might impact the risk of diabetes through the inflammatory response [814]. A recent randomized controlled trial found that among 100 diabetes patients, vitamin D supplementation led to an increase in $25(\mathrm{OH}) \mathrm{D}$ concentration and decrease in measured inflammatory biomarkers [12]. However, other studies found no association between vitamin $\mathrm{D}$ supplementation and inflammatory biomarkers [11-14]. Studies to date have limited generalizability due to using small samples [11, 12 , 14]. In the present study, we used data from a nationally representative sample to explore the association between 25(OH)D and T2DM and HbAlc and test whether these associations were mediated by serum systemic inflammation.

\section{Methods}

2.1. Study Design. Data from 2001-2006 National Health and Nutrition Examination Survey (NHANES) were used. The NHANES are conducted by the National Center for Health Statistics (NCHS), part of the Centers for Disease Control and Prevention (CDC). Survey participants from the US 
noninstitutionalized civilian population were selected using a stratified multistage probability sample design. Participants were interviewed and invited for a clinical examination. Physical examinations and collection of blood samples were conducted in a mobile examination clinic (MEC) [15]. All serum specimens were processed, stored, and shipped to the Division of Laboratory Sciences, National Center for Environmental Health, CDC, using standardized measurement and analysis. The unweighed response rates for 20012006 NHANES were $\geq 76 \%$ [16]. The NCHS Ethics Review Board approved the survey, and participants provided written informed consent [17].

Serum $25(\mathrm{OH}) \mathrm{D}$ concentration was measured using a radioimmunoassay kit (DiaSorin, Stillwater, MN) [18]. Serum $25(\mathrm{OH}) \mathrm{D}$ concentration is used to estimate total intake of vitamin D from cutaneous synthesis and dietary intake [19]. Serum HbAlc was measured using a high-performance liquid chromatography system. T2DM was defined on the basis of the American Diabetes Association criteria [20]. Patients who have fasting plasma glucose concentration $\geq 126 \mathrm{mg} / \mathrm{dL}$ or two-hour plasma glucose $\geq 200 \mathrm{mg} / \mathrm{dL}$ during an oral glucose tolerance test or $\mathrm{HbAlc} \geq 6.5 \%$ or an answer of "yes" to any of the following questions were diagnosed as having T2DM: (1) "Other than during pregnancy, have you ever been told by a doctor or other health professional that you have diabetes or sugar diabetes?"; (2) "Are you taking insulin now?"; (3) "Are you taking diabetic pills to lower your blood sugar?" Serum CRP was measured by latex-enhanced nephelometry using a Behring Nephelometer Analyzer System (Behring Diagnostics Inc., Somerville, NJ).

2.2. Measurements of Covariates. Information on age, race/ ethnicity, sex, education level, physical activity, and family history of diabetes was obtained using standard survey questionnaires. Season of examination was classified as winter if the period of examination was between November 1 and April 30 or summer if between May 1 and October 31. Physical activity per day was grouped on a scale of 1 to 4 (least vigorous to most vigorous). Family history of diabetes was defined if a participant answered "yes" to the following question: including living and deceased, were any of your biological relatives, that is, blood relatives, including grandparents, parents, brothers, and sisters, ever told by a health professional that they had diabetes?

Anthropometric measurements and blood pressure (BP) were obtained by trained researchers during a physical examination [15]. Waist circumference (WC) was measured at a point immediately above the iliac crest on the midaxillary line at minimal respiration to the nearest $0.1 \mathrm{~cm}$ [17]. Resting systolic and diastolic BP (SBP and DBP) were measured three to four times with a mercury sphygmomanometer. When more than one BP measurements were available, the average SBP and DBP were calculated. Serum high-density lipoprotein (HDL) cholesterol was measured using a direct immunoassay method.

2.3. Inclusion and Exclusion Criteria. Participants who were interviewed and examined in MEC and did not have data on age, sex, season, education, serum $25(\mathrm{OH}) \mathrm{D}$ concentration, CRP, and HbAlc were excluded from the present study $(n=1090)$. Participants missing covariate information (WC, education, physical activity, family history of diabetes, HDL, SBP, and DBP) were excluded as well $(n=1,407)$.

Race/ethnicity was adjusted in multivariate analysis due to the strong association between skin pigmentation and lower 25(OH)D concentration $[21,22]$ and associations with socioeconomic status and behaviors [23]. The final analyzed sample was 8,655 participants.

2.4. Statistical Analysis. First we examined associations between 25(OH)D and T2DM before and after adjustment for CRP. Serum 25(OH)D status was classified as insufficient $(<50 \mathrm{nmol} / \mathrm{L})$ and sufficient $(50-125 \mathrm{nmol} / \mathrm{L})$. To test the association between $25(\mathrm{OH}) \mathrm{D}$ status and T2DM, we used multivariate logistic regression models. Second, further adjustment analysis was conducted in order to control for multiple confounders. In this analysis, we adjusted for age (years), race/ethnicity (non-Hispanic White or non-Hispanic Black), season of examination (winter or summer), education level (less than high school, high school diploma, or some college education), physical activity (1 to 4 ), smoking status (never smoker, former smoker, or current smoker), SBP $(\mathrm{mm} \mathrm{Hg}), \mathrm{HDL}(\mathrm{mmol} / \mathrm{L}), \mathrm{WC}(\mathrm{cm})$, and family history of diabetes (yes or no). We repeated the analysis with adjustment for log-CRP ( $\mathrm{nmol} / \mathrm{L}$ ) to evaluate the mediation effect of inflammation. Third, multivariate path analysis was performed in order to examine direct and indirect associations between $25(\mathrm{OH}) \mathrm{D}(\mathrm{nmol} / \mathrm{L})$ and $\mathrm{HbAlc}(\%)$. In the study, a theoretical path model was specified based on prior theory [24] and standard procedures were followed to test whether the data fit the theoretical model including ensuring that conditions were satisfied for unbiased parameter estimation and interpretation of path model fit [25]. Standardized summary of the average covariance residuals (root mean square error of approximation (RMSEA)), standardized difference between the observed correlation and the predicted correlation (standardized root mean square residual (SRMSR)), Bentler comparative fit index (BCFI), the proportion of the observed covariance, and adjusted goodness of fit index (AGFI) were used to evaluate whether a multivariate model meets the modeling requirement. Generally accepted values for fit indices are RMSEA $<0.10$ [26], SRMSR $<0.08$ [27], BCFI > 0.90 [28], and AGFI > 0.90 [29].

Figure 1 depicts the hypothesized relationships in the present study. Single-headed arrows indicate a direct effect from exogenous to endogenous variable, and a doubleheaded arrow indicates a correlation among exogenous variables (Figure 1). Three endogenous variables are HbAlc, $25(\mathrm{OH}) \mathrm{D}$ concentration, and log-CRP. Values of CRP were log-transformed to improve normality. Six exogenous variables were race/ethnicity (non-Hispanic Black versus nonHispanic White), family history of diabetes (yes or no), age (years), WC (cm), SBP ( $\mathrm{mm} \mathrm{Hg})$, and HDL $(\mathrm{mmol} / \mathrm{L})$. Season, education, physical activity, and DBP were dropped from the path model because of nonsignificance. In order to 


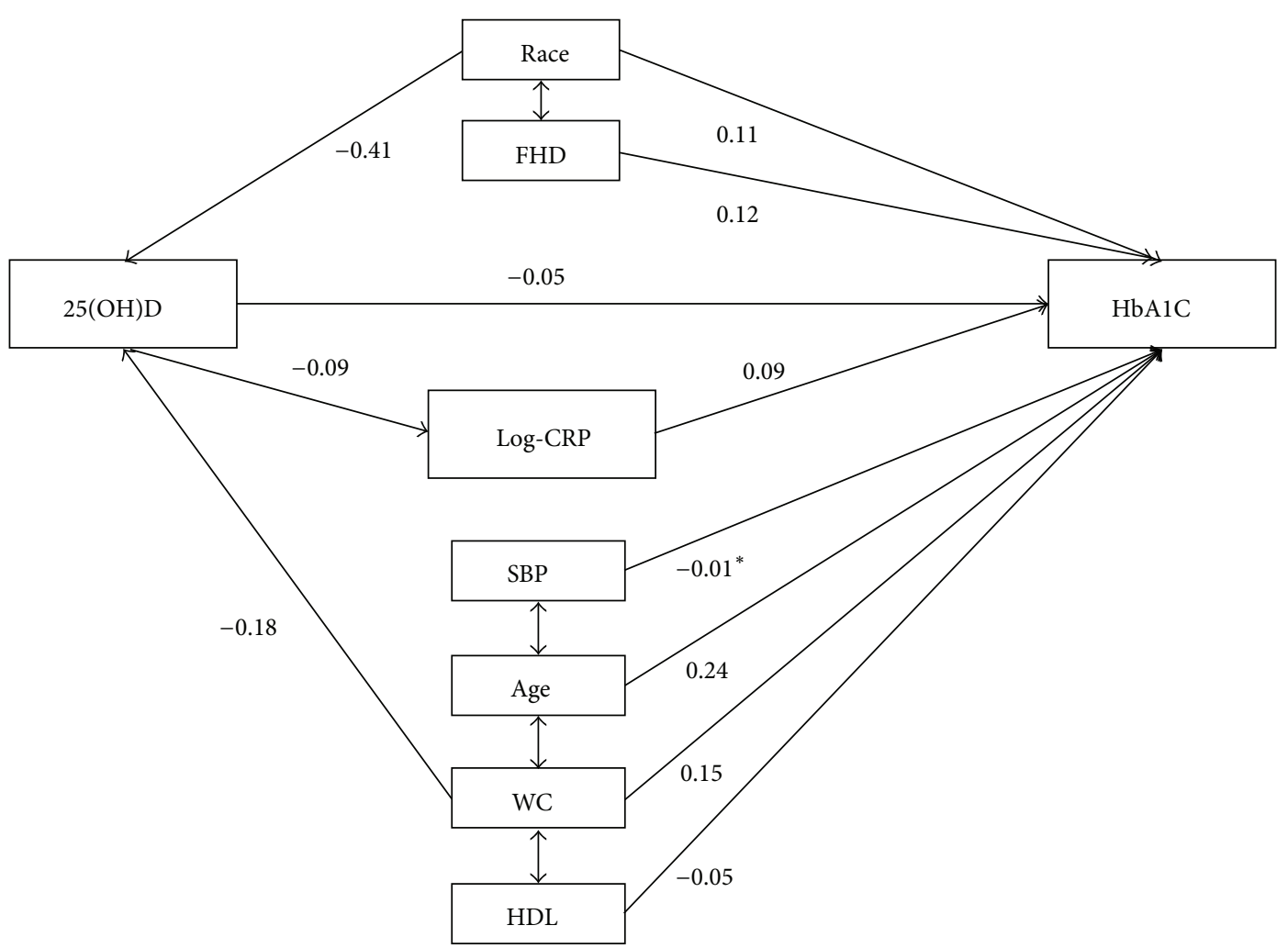

FIGURE 1: Path analysis diagram shown with standardized coefficients from the model for males, NHANES 2001-2006.

assess the sensitivity of results to departures from multivariate normality when using maximum likelihood estimation (MLE), we retested our path model using weighted-least squares regression (a robust estimation procedure) [30]; however, the results were the same. It is likely due to the large sample size [31], thus the latter are not reported here.

All data analyses were stratified by sex because of sex difference in serum $25(\mathrm{OH}) \mathrm{D}$ concentration and T2DM rate [32-34]. SAS 9.2 (SAS Institute, Cary, NC) was used in all data analyses.

\section{Results}

Table 1 shows the characteristics of participants stratified by sex. Males tended to be older, less educated, more physically active, and less likely to have a blood relative with diabetes. In addition, males were more likely to have a greater WC, lower serum 25(OH)D concentration, higher HbAlc, lower serum CRP, lower HDL, higher systolic blood pressure, and higher diastolic blood pressure.

Results from multiple logistic regression analyses indicate that $25(\mathrm{OH}) \mathrm{D}$ insufficiency was significantly associated with a $20.7 \%(\mathrm{OR}=1.207,95 \% \mathrm{CI}: 1.203,1.210)$ and $77.3 \%(\mathrm{OR}=$ $1.773,95 \%$ CI: 1.731, 1.740) increased odds of T2DM in females and males, respectively (Table 2). Adjustment for log-CRP in males slightly attenuated the association $(\mathrm{OR}=1.736,95 \% \mathrm{CI}$ : $1.731,1.740)$, but we observed no change in females.

Table 3 shows the model fit statistics of path models. In males, the path models fitted well indicated by RMSEA $=0.09$,
SRMSR $=0.05$, AGFI $=0.91$, and BCFI $=0.90$. However, the path model did not fit well for females as compared to the model for males. The results from path analysis suggest that there was no or a weak mediation effect of CRP on the association between serum 25(OH)D and HbAlc (path coefficient $=0.004,95 \% \mathrm{CI}:-0.03,0.03, P=0.28$, Table 4 ).

Figure 1 shows the proposed path model and standardized coefficients. All path coefficients were statistically significant except for the path between SBP and HbAlc (path coefficient $=-0.01,95 \%$ CI: $-0.04,0.02)$. Serum 25(OH)D concentration had a negatively direct association with $\mathrm{HbAlc}$ (path coefficient $=-0.05,95 \% \mathrm{CI}:-0.08,-0.02$ ). The indirect association of $25(\mathrm{OH}) \mathrm{D}$ with $\mathrm{HbAlc}$ was statistically significant (path coefficient $=-0.008, P<0.0001$ ). By dividing the indirect effect by the total effect, a $14.9 \%$ of the association between $25(\mathrm{OH}) \mathrm{D}$ and HbAlc could be attributable to CRP (i.e., a mediated effect).

\section{Discussion}

Using data from a large, nationally representative sample of adults aged 20 and older, the main findings of the present study not only support that decreased serum $25(\mathrm{OH}) \mathrm{D}$ concentration is significantly associated with prevalent T2DM and elevated HbAlc but also extend previous studies by examining and identifying that there is a possible mediation effect of systemic inflammation on the association between $25(\mathrm{OH}) \mathrm{D}$ and metabolic dysfunction in males. This result is independent of a set of covariates, including 
TABLE 1: Characteristics of participants by sex, NHANES 2001-2006.

\begin{tabular}{|c|c|c|c|}
\hline Characteristic & Male & Female & $P$ value* \\
\hline Unweighed sample size & 4181 & 4474 & \\
\hline Age (years) & $51.2(18.6)$ & $49.1(19.2)$ & $<0.0001$ \\
\hline Sample recruited by season & & & 0.69 \\
\hline Winter & $1589(38.0)$ & $1682(37.6)$ & \\
\hline Summer & $2592(62.0)$ & $2792(62.4)$ & \\
\hline Race/ethnicity & & & 1.0 \\
\hline Non-Hispanic White & $3070(73.4)$ & $3285(73.4)$ & \\
\hline Non-Hispanic Black & $1111(26.6)$ & $1189(26.6)$ & \\
\hline Education & & & 0.02 \\
\hline Less than high school & $858(20.5)$ & $822(18.4)$ & \\
\hline High school diploma & $1100(26.3)$ & $1157(25.9)$ & \\
\hline Some college & $2223(53.2)$ & $2495(55.8)$ & \\
\hline Physical activity (1: least vigorous, 4 : most vigorous) & $2.2 \pm 0.9$ & $2.0 \pm 0.7$ & $<0.0001$ \\
\hline Waist circumference $(\mathrm{cm})$ & $100.8 \pm 14.9$ & $95.3 \pm 15.7$ & $<0.0001$ \\
\hline Serum 25(OH)D (nmol/L) & $56.5 \pm 21.8$ & $57.6 \pm 25.9$ & 0.03 \\
\hline Hemoglobin HbAlc $(\%)^{* *}$ & $5.4(5.2-5.7)$ & $5.3(5.1-5.6)$ & $<0.0001$ \\
\hline Serum C-reactive protein $(\mathrm{nmol} / \mathrm{L})^{* *}$ & $16.2(6.7-36.2)$ & $26.7(10.5-59.0)$ & $<0.0001$ \\
\hline Family history of diabetes & & & $<0.0001$ \\
\hline Yes & $1785(42.7)$ & $2225(49.7)$ & \\
\hline No & $2396(57.3)$ & $2249(50.3)$ & \\
\hline HDL cholesterol (mmol/L) & $1.27 \pm 0.36$ & $1.57 \pm 0.44$ & $<0.0001$ \\
\hline Systolic blood pressure ( $\mathrm{mmHg})$ & $127.0 \pm 17.6$ & $124.5 \pm 22.4$ & $<0.0001$ \\
\hline Diastolic blood pressure $(\mathrm{mmHg})$ & $72.42 \pm 12.5$ & $69.2 \pm 12.4$ & $<0.0001$ \\
\hline
\end{tabular}

Data are presented as means \pm SD or median (IQR) $)^{* *}$ or $n(\%)$.

${ }^{*} P$ value represents differences in means \pm SD or median (IQR) or proportions using $t$-test or Wilcoxon rank-sum test or Pearson's chi-squared test, respectively, using a two-tailed test.

TABLE 2: Odds ratios of the association between serum 25(OH)D sufficiency and T2DM before and after adjustment for C-reactive protein by sex, NHANES 2001-2006.

\begin{tabular}{lcc}
\hline Sex & Model & Odds ratio $(95 \% \mathrm{CI})$ \\
\hline \multirow{2}{*}{ Females } & Model 1 & $1.207(1.203,1.210)$ \\
& Model 2 & $1.207(1.203,1.210)$ \\
\multirow{2}{*}{ Males } & Model 1 & $1.773(1.769,1.778)$ \\
& Model 2 & $1.736(1.731,1.740)$ \\
\hline
\end{tabular}

${ }^{1}$ Model 1: adjusted for age, race/ethnicity, season of examination, education level, physical activity, smoking status, systolic BP, high-density lipoprotein cholesterol, waist circumference, and family history of diabetes.

${ }^{2}$ Model 2: adjusted for log-CRP in addition to the variables from Model 1.

age, race/ethnicity, season of examination, education, lipid profiles, and behavior risk factors.

In the present study, we did not observe a significant mediation effect of serum CRP on the associations of serum 25(OH)D with T2DM and HbAlc in females. Although we are unable to further test this sex difference using the present limited data, there may be more complex predictors in females, such as reproductive history, female hormone use, and the degree of sensitivity to a certain disease and medication. Additional studies will be required to further address these questions.
The mechanisms by which serum $25(\mathrm{OH}) \mathrm{D}$ may have a protective effect on risk of metabolic dysfunction are still being studied. It has been suggested that vitamin D may influence the nuclear transcription factors necessary for the generation and action of cytokines [35]. Appropriate levels of serum vitamin $\mathrm{D}$ concentration may have a direct effect to help cells less sensitive to particular nuclear factors which might cause insulin resistance [36]. Insulin resistance and decreased pancreatic $\beta$-cell function are the primary pathways by which vitamin $\mathrm{D}$ is suggested to impact glucose homeostasis [5]. Vitamin D may also have a function by reducing the risk effect of inflammation on metabolic diseases. In the present study, the associations between serum 25(OH)D and T2DM and HbAlc were significantly reduced after adjustment for serum CRP; in other words, CRP may have a mediation effect on the association between vitamin $\mathrm{D}$ and metabolic dysfunction in males.

Increasing evidence supports the hypothesis that vitamin D may play a pivotal role in the pathophysiology of glucose metabolism. Although these mechanisms are not fully understood, pathways may include impaired pancreatic $\beta$ cell function, insulin resistance, and systemic inflammation. Evidence for an inverse association between serum 25(OH)D and type 2 diabetes has been derived from many crosssectional studies. However, the results have not been internally and externally consistent. Depending on the outcome 
TABLE 3: Model fit indices for path analysis models by sex, NHANES 2001-2006.

\begin{tabular}{lccc}
\hline Model fit index & \multirow{2}{*}{ Good fit threshold levels } & \multicolumn{2}{c}{ Model fit statistic value } \\
Fales & 0.09 & 0.14 \\
\hline Root mean square error approximation (RMSEA) & $<0.10$ & 0.05 & 0.07 \\
Standardized root mean square residual (SRMSR) & $<0.08$ & 0.91 & 0.83 \\
Adjusted goodness of fit (AGFI) & $>0.90$ & 0.90 & 0.86 \\
Bentler comparative fit index (BCFI) & $>0.90$ & & \\
\hline
\end{tabular}

TABLE 4: Standardized path coefficients and 95\% confidence intervals by sex.

\begin{tabular}{|c|c|c|c|c|}
\hline Path & $\begin{array}{c}\text { Path } \\
\text { coefficient }\end{array}$ & \multicolumn{2}{|c|}{$95 \%$ CI } & $P$ value ${ }^{*}$ \\
\hline \multicolumn{5}{|c|}{ Males } \\
\hline \multicolumn{5}{|c|}{ Standardized effects on HbAlc } \\
\hline $25(\mathrm{OH}) \mathrm{D} \rightarrow \mathrm{HbAlc}$ & -0.05 & -0.08 & -0.02 & 0.003 \\
\hline Log-CRP $\rightarrow$ HbAlc & 0.09 & 0.06 & 0.12 & $<0.0001$ \\
\hline \multicolumn{5}{|c|}{ Standardized effects on log-CRP } \\
\hline 25(OH)D $\rightarrow$ Log-CRP & -0.09 & -0.12 & -0.06 & $<0.0001$ \\
\hline \multicolumn{5}{|c|}{ Standardized effects on $25(\mathrm{OH}) \mathrm{D}$} \\
\hline $\mathrm{WC} \rightarrow 25(\mathrm{OH}) \mathrm{D}$ & -0.18 & -0.21 & -0.15 & $<0.0001$ \\
\hline Race $\rightarrow 25(\mathrm{OH}) \mathrm{D}$ & -0.41 & -0.44 & -0.39 & $<0.0001$ \\
\hline \multicolumn{5}{|c|}{ Females } \\
\hline \multicolumn{5}{|c|}{ Standardized effects on HbAlc } \\
\hline 25(OH)D $\rightarrow$ HbAlc & 0.004 & -0.03 & 0.03 & 0.28 \\
\hline Log-CRP $\rightarrow$ HbAlc & 0.05 & 0.02 & 0.07 & 0.0004 \\
\hline \multicolumn{5}{|c|}{ Standardized effects on Log-CRP } \\
\hline $25(\mathrm{OH}) \mathrm{D} \rightarrow$ Log-CRP & -0.13 & -0.16 & -0.10 & $<0.0001$ \\
\hline
\end{tabular}

25(OH)D: 25-hydroxyvitamin D, WC: waist circumference, log-CRP: log C-reactive protein.

${ }^{*} P$ value based on two-tailed test.

measures, results may vary within a study. For example, in the Baynes et al. study [37], serum 25(OH)D was found to be associated with 1-hour glucose after a standard $75 \mathrm{~g}$ oral glucose tolerance test (OGTT) but not fasting plasma glucose. Findings from the Kuopio Ischaemic Heart Disease Risk Factor Study indicate that serum 25(OH)D concentration was inversely associated with OGTT 2-hour glucose concentration after adjustment for age, sex, and year of examination [38]. However, other important covariates, such as race, SBP, and obesity, were not adjusted in their study. In our present study, taking the advantage of data from a large-scale nationally representative sample, we were able to take account of all these covariates in our multivariate and path analysis models. The findings of our study extend previous studies and add new evidence to the research field.

Most previous studies had been limited to their case definitions, including T2DM which they defined on the basis of participants' self-reported data. This approach may lead to a serious underestimation of the true prevalence of T2DM because of possible information bias and the classifications without support from blood sample tests [14]. In our present study, we were able to use results from blood tests to classify the prevalence of T2DM. The main limitation of our present study is that the findings are driven from a study with crosssectional design. Therefore, all results from the present study cannot be interpreted as a cause-effect association, although this association has been supported by few longitudinal studies [38-43]. In conclusion, using a large communitybased general population sample, the present study adds new evidence to the literature on the association between decreased vitamin D and risk of T2DM, and this association may be mediated by systemic inflammation in males. Further longitudinal prospective and randomized clinical trials are needed to confirm the present findings.

\section{Acknowledgment}

This study was conducted using data from the National Health and Nutrition Examination Survey and obtained from the National Center for Health Statistics (NCHS). The opinions expressed in this paper are those of the authors and do not necessarily reflect the views of NCHS. 


\section{References}

[1] A. G. Pittas, M. Chung, T. Trikalinos et al., "Systematic review: vitamin D and cardiometabolic outcomes," Annals of Internal Medicine, vol. 152, no. 5, pp. 307-314, 2010.

[2] J. Mitri, M. D. Muraru, and A. G. Pittas, "Vitamin D and type 2 diabetes: a systematic review," European Journal of Clinical Nutrition, vol. 65, no. 9, pp. 1005-1015, 2011.

[3] A. C. Ross, C. L. Taylor, A. L. Yaktine, and H. B. Del Valle, Dietary Reference Intakes for Calcium and Vitamin D, National Academies Press, 2011.

[4] A. Ashraf and J. A. Alvarez, "Role of vitamin D in insulin secretion and insulin sensitivity for glucose homeostasis," International Journal of Endocrinology, vol. 2010, Article ID 351385, 18 pages, 2010.

[5] A. G. Pittas, J. Lau, F. B. Hu, and B. Dawson-Hughes, "The role of vitamin $\mathrm{D}$ and calcium in type 2 diabetes. A systematic review and meta-analysis," Journal of Clinical Endocrinology and Metabolism, vol. 92, no. 6, pp. 2017-2029, 2007.

[6] K. C. Chiu, A. Chu, V. L. W. Go, and M. F. Saad, "Hypovitaminosis $\mathrm{D}$ is associated with insulin resistance and $\beta$ cell dysfunction," The American Journal of Clinical Nutrition, vol. 79, no. 5, pp. 820-825, 2004.

[7] J. Sun, J. Kong, Y. Duan et al., "Increased NF- $\kappa$ B activity in fibroblasts lacking the vitamin D receptor," The American Journal of Physiology-Endocrinology and Metabolism, vol. 291, no. 2, pp. E315-E322, 2006.

[8] C. E. A. Chagas, M. C. Borges, L. A. Martini, and M. M. Rogero, "Focus on vitamin D, inflammation and type 2 diabetes," Nutrients, vol. 4, no. 1, pp. 52-67, 2012.

[9] M. Flores, "A role of vitamin D in low-intensity chronic inflammation and insulin resistance in type 2 diabetes mellitus?" Nutrition Research Reviews, vol. 18, no. 2, pp. 175-182, 2005.

[10] A. Festa, A. J. G. Hanley, R. P. Tracy, R. D’Agostino Jr., and S. M. Haffner, "Inflammation in the prediabetic state is related to increased insulin resistance rather than decreased insulin secretion," Circulation, vol. 108, no. 15, pp. 1822-1830, 2003.

[11] C. Luo, J. Wong, M. Brown, M. Hooper, L. Molyneaux, and D. K. Yue, "Hypovitaminosis D in Chinese type 2 diabetes: lack of impact on clinical metabolic status and biomarkers of cellular inflammation," Diabetes and Vascular Disease Research, vol. 6, no. 3, pp. 194-199, 2009.

[12] S. Shab-Bidar, T. R. Neyestani, A. Djazayery et al., "Improvement of vitamin $\mathrm{D}$ status resulted in amelioration of biomarkers of systemic inflammation in the subjects with type 2 diabetes," Diabetes/Metabolism Research and Reviews, vol. 28, no. 5, pp. 424-430, 2012.

[13] A. G. Pittas, S. S. Harris, P. C. Stark, and B. Dawson-Hughes, "The effects of calcium and vitamin D supplementation on blood glucose and markers of inflammation in nondiabetic adults," Diabetes Care, vol. 30, no. 4, pp. 980-986, 2007.

[14] M. Cigolini, M. P. Iagulli, V. Miconi, M. Galiotto, S. Lombardi, and G. Targher, "Serum 25-hydroxyvitamin D3 concentrations and prevalence of cardiovascular disease among type 2 diabetic patients," Diabetes Care, vol. 29, no. 3, pp. 722-724, 2006.

[15] Centers for Disease Control and Prevention and National Center for Health Statistics, National Health and Nutrition Examination Survey Examination Protocol, U.S. Department of Health and Human Services, Centers for Disease Control and Prevention, Hyattsville, Md, USA, 2001-2006.

[16] Centers for Disease Control and Prevention and National Center for Health Statistics, National Health and Nutrition
Examination Survey Data, U.S. Department of Health and Human Services, Centers for Disease Control and Prevention, Hyattsville, Md, USA, 2001-2006.

[17] Centers for Disease Control and Prevention and National Center for Health Statistics, National Health and Nutrition Examination Survey Questionnaire, U.S. Department of Health and Human Services, Centers for Disease Control and Prevention, Hyattsville, Md, USA, 2001-2006.

[18] Centers for Disease Control and Prevention and National Center for Health Statistics, National Health and Nutrition Examination Laboratory Protocol, U.S. Department of Health and Human Services, Centers for Disease Control and Prevention, Hyattsville, Md, USA, 2001-2006.

[19] B. W. Hollis, "Assessment of vitamin D nutritional and hormonal status: what to measure and how to do it," Calcified Tissue International, vol. 58, no. 1, pp. 4-5, 1996.

[20] American Diabetes Association, "Standards of medical care in diabetes-2010," Diabetes Care, vol. 33, supplement 1, pp. S11S61, 2010.

[21] K. M. Egan, L. B. Signorello, H. M. Munro, M. K. Hargreaves, B. W. Hollis, and W. J. Blot, "Vitamin D insufficiency among African-Americans in the southeastern United States: implications for cancer disparities (United States)," Cancer Causes and Control, vol. 19, no. 5, pp. 527-535, 2008.

[22] S. Nessvi, L. Johansson, J. Jopson et al., "Association of 25hydroxyvitamin D3 levels in adult new zealanders with ethnicity, skin color and self-reported skin sensitivity to sun exposure," Photochemistry and Photobiology, vol. 87, no. 5, pp. 1173-1178, 2011.

[23] C. E. Moore, M. M. Murphy, and M. F. Holick, "Vitamin D intakes by children and adults in the United States differ among ethnic groups," Journal of Nutrition, vol. 135, no. 10, pp. 24782485, 2005.

[24] K. A. Bollen, Structural Equation Models, Wiley Online Library, 1998.

[25] R. B. Kline, Principles and Practice of Structural Equation Modeling, The Guilford Press, 2010.

[26] M. W. Browne and R. Cudeck, "Alternative ways of assessing model fit," Sociological Methods Research, vol. 21, no. 2, pp. 230$258,1992$.

[27] L. Hu and P. M. Bentler, "Cutoff criteria for fit indexes in covariance structure analysis: conventional criteria versus new alternatives," Structural Equation Modeling, vol. 6, no. 1, pp. 155, 1999.

[28] P. M. Bentler, "Comparative fit indexes in structural models," Psychological Bulletin, vol. 107, no. 2, pp. 238-246, 1990.

[29] J. F. Hair, Multivariate Data Analysis, Pearson Prentice Hall, Upper Saddle River, NJ, USA, 6th edition, 2006.

[30] U. H. Olsson, T. Foss, S. V. Troye, and R. D. Howell, "The performance of ML, GLS, and WLS estimation in structural equation modeling under conditions of misspecification and nonnormality," Structural Equation Modeling, vol. 7, no. 4, pp. 557-595, 2000.

[31] M. Lei and R. G. Lomax, "The effect of varying degrees of nonnormality in structural equation modeling," Structural Equation Modeling, vol. 12, no. 1, pp. 1-27, 2005.

[32] J. G. Robinson, J. E. Manson, J. Larson et al., "Lack of association between 25(OH)D levels and incident type 2 diabetes in older women," Diabetes Care, vol. 34, no. 3, pp. 628-634, 2011.

[33] I. H. de Boer, L. F. Tinker, S. Connelly et al., "Calcium plus vitamin $\mathrm{D}$ supplementation and the risk of incident diabetes in 
the women's health initiative," Diabetes Care, vol. 31, no. 4, pp. 701-707, 2008.

[34] P. Knekt, M. Laaksonen, C. Mattila et al., "Serum vitamin D and subsequent occurrence of type 2 diabetes," Epidemiology, vol. 19, no. 5, pp. 666-671, 2008.

[35] R. Riachy, B. Vandewalle, J. K. Conte et al., "1,25-dihydroxyvitamin D3 protects RINm5F and human islet cells against cytokine-induced apoptosis: implication of the antiapoptotic protein A20," Endocrinology, vol. 143, no. 12, pp. 4809-4819, 2002.

[36] A. G. Pittas, N. A. Joseph, and A. S. Greenberg, "Adipocytokines and insulin resistance," Journal of Clinical Endocrinology and Metabolism, vol. 89, no. 2, pp. 447-452, 2004.

[37] K. C. R. Baynes, B. J. Boucher, E. J. M. Feskens, and D. Kromhout, "Vitamin D, glucose tolerance anal insulinaemia in elderly men," Diabetologia, vol. 40, no. 3, pp. 344-347, 1997.

[38] A. R. Hurskainen, J. K. Virtanen, T. P. Tuomainen, T. Nurmi, and S. Voutilainen, "Association of serum 25-hydroxyvitamin $\mathrm{D}$ with type 2 diabetes and markers of insulin resistance in a general older population in Finland," Diabetes/Metabolism Research and Reviews, vol. 28, no. 5, pp. 418-423, 2012.

[39] R. Scragg, M. Sowers, and C. Bell, "Serum 25-hydroxyvitamin $\mathrm{D}$, diabetes, and ethnicity in the third national health and nutrition examination survey," Diabetes Care, vol. 27, no. 12, pp. 2813-2818, 2004.

[40] E. S. Ford, U. A. Ajani, L. C. McGuire, and S. Liu, "Concentrations of serum vitamin D and the metabolic syndrome among U.S. adults," Diabetes Care, vol. 28, no. 5, pp. 1228-1230, 2005.

[41] V. Hirani, "Relationship between vitamin D and hyperglycemia in older people from a nationally representative population survey," Journal of the American Geriatrics Society, vol. 59, no. 10, pp. 1786-1792, 2011.

[42] M. Snijder, R. van Dam, M. Visser, D. Deeg, J. Seidell, and P. Lips, “To: Mathieu C, Gysemans C, Giulietti A, Bouillon R (2005) vitamin D and diabetes," Diabetologia, vol. 49, no. 1, pp. 217-218, 2006.

[43] R. Hidayat, S. Setiati, and P. Soewondo, "The association between vitamin $\mathrm{D}$ deficiency and type 2 diabetes mellitus in elderly patients.," Acta Medica Indonesiana, vol. 42, no. 3, pp. 123-129, 2010. 


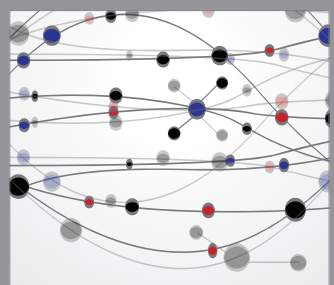

The Scientific World Journal
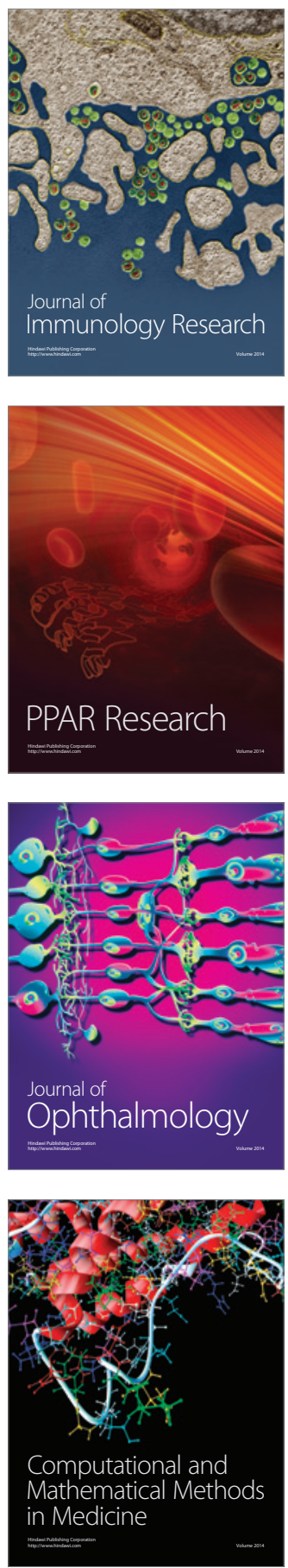

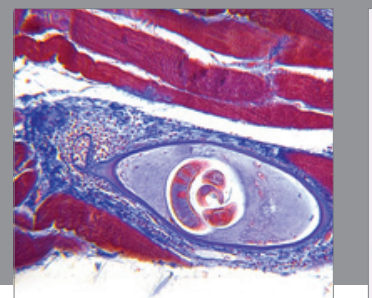

Gastroenterology

Research and Practice
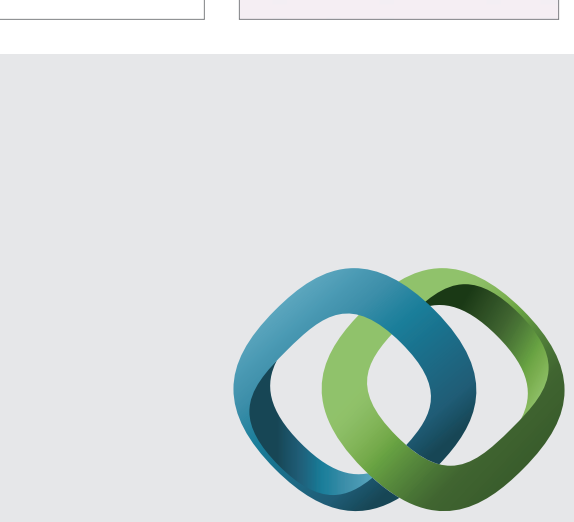

\section{Hindawi}

Submit your manuscripts at

http://www.hindawi.com
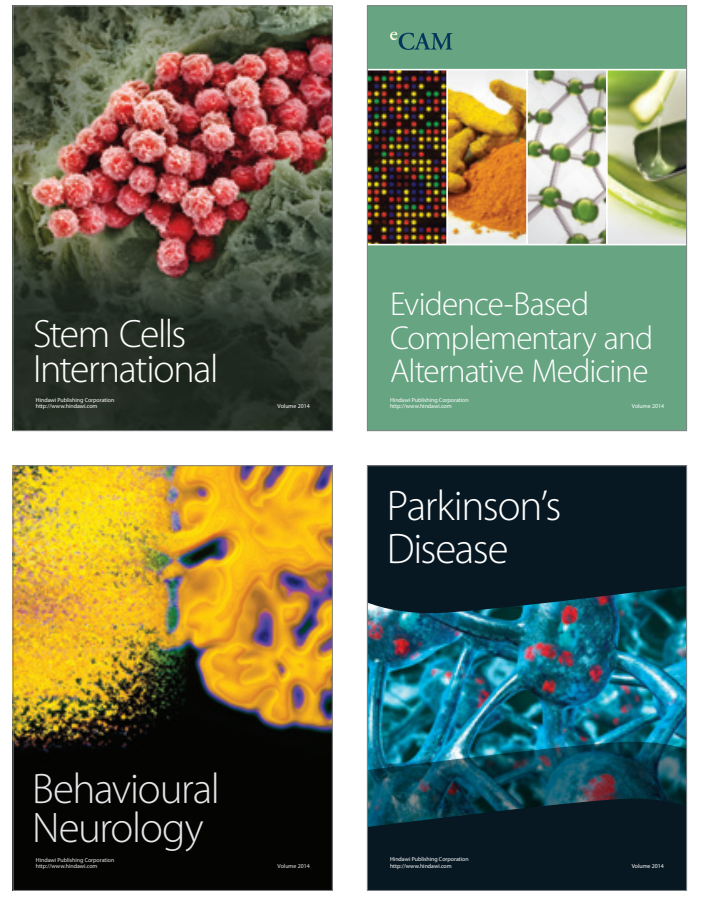
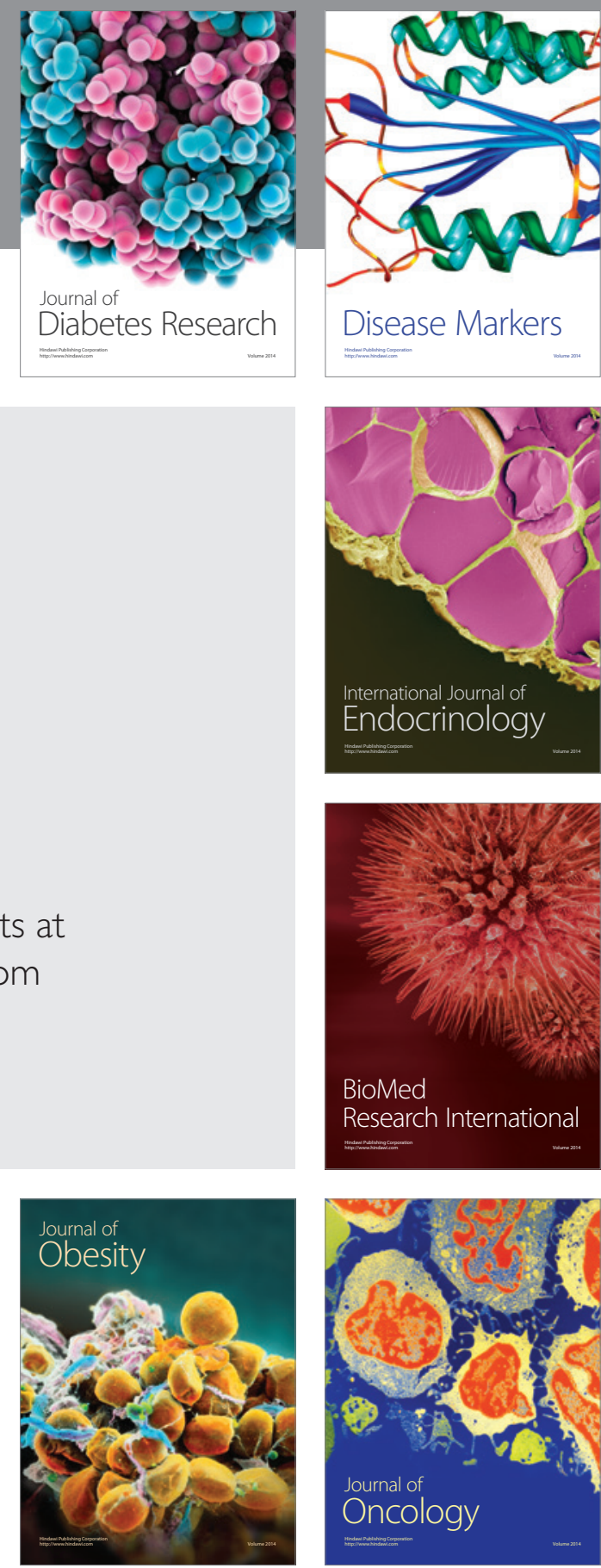

Disease Markers
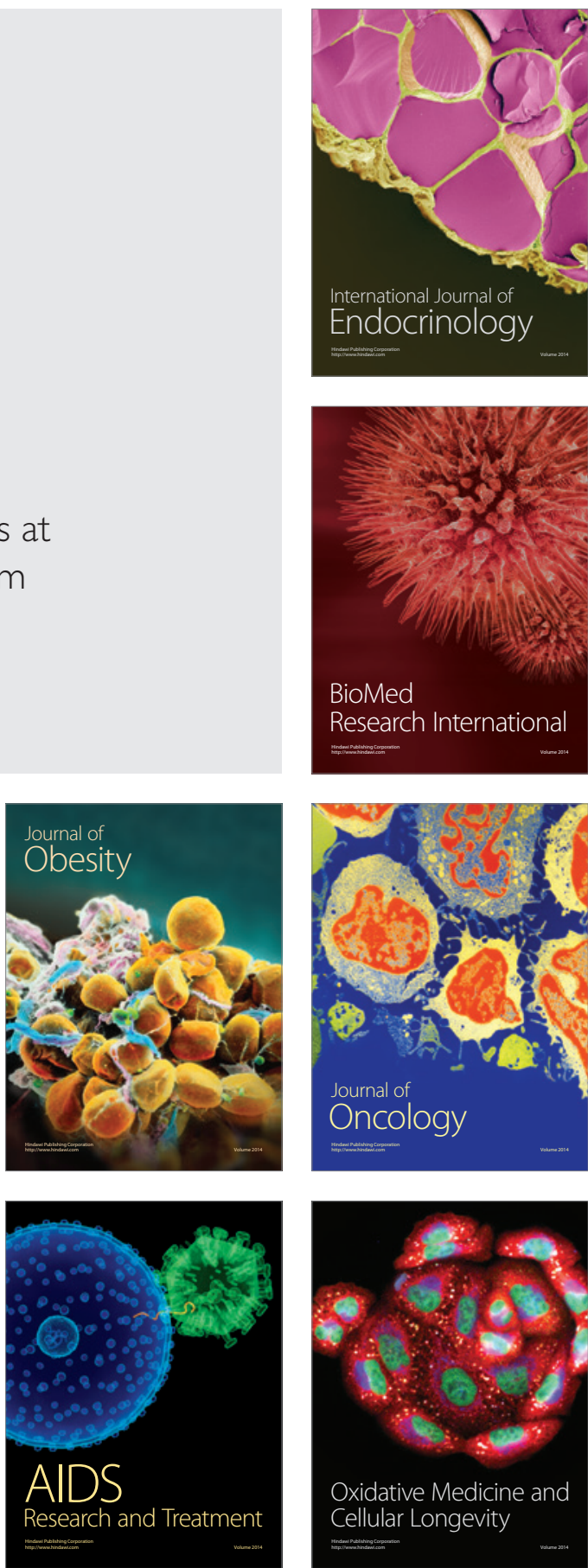